\title{
Opportunities and Support for College and University Libraries
}

\section{Address at the Dedication of the Addition to the Library of the University of North Carolina, April I8, 1952}

Dr. Jones is professor of English, Harvard University.

$A^{S}$ WE PONDER the significance of the $A$ exercises in which we are engaged, I am confident the feeling we have must be one of admiration for extraordinary achievement. For the achievement is extraordinary. As late as the opening of the present century there were only 30,000 books in the Library of the University of North Carolina; today, there are three-fifths of a million. When I first came to this University in the middle twenties, the old Carnegie Building sufficed to house the collection; when I reluctantly left in 1930 , the University was justly proud of a library of 250,000 volumes and of a new and modern building. Today the number of books has more than doubled; and the building has likewise doubled in capacity and more than doubled in convenience, containing not only stack room for more than a million volumes, but also one of the most adequate arrangements in the entire South for the work of scholars, writers, bibliographical specialists, and librarians. A vast collection of manuscripts assembled by the patient industry of historians and having to do with the development of the State and of the region is housed here. So, too, are a great collection of printed materials about the State, an important library of rare books, and technological facilities for extracting every ounce of intellectual juice from printed page and written word. But more than the book is represented. Here are also such material embodiments of the past as a room illustrating the life of Sir Walter Raleigh's time; another illustrating the life of pioneer settlers; and, with them, a third-the Bull's Head Bookshop-illustrating the place and use of books in contemporary society. All this has come into being in a community which, in the eighteenth century, the aristocratic Colonel William Byrd, when he wrote his diverting History of the Dividing Line, characterized as Lubberland.

The whirligig of time brings in his revenges if you will but wait; and although comparisons are, as Mrs. Malaprop justly said, odorous, I cannot refrain from noting that, according to figures in the latest American Library Directory, the State University Library in Lubberland now possesses by actual count almost as many books as does the Library of the University founded by Thomas Jefferson. Of course this is not the whole story; and rivalry is to be deprecated in a period when librarians are working towards cooperation. Nevertheless, there is enough of the old Adam in all of us to inquire anxiously, in the fall of every year, about the respective strength of Tarheel and Cavalier in a college activity having only a remote relation to the writing 
of doctoral dissertations. Why should the football coaches have all the fun of comparative judgments?

The development here represented is remarkable in terms of the twentieth century. It becomes even more remarkable when one goes more deeply into the history of the State, and, parenthetically, one cannot go very far back into the history of this or any other state without a library. Some fiftyseven years ago Stephen B. Weeks published his classic article on "Libraries and Literature in North Carolina in the Eighteenth Century." No account of the cultural life of a commonwealth could be more discouraging. Weeks found occasional books turning up in the inventories of some families in North Carolina; he found a few libraries here and there; he managed to trace a small collection of books sent into the colony by the Rev. Thomas Bray, a collection so little valued that it suffered neglect and spoliation-in 1712 Rainsford said the books had been "all dispersed and lost by those wretches that do not consider the benefit of so valuable a gift"-and Weeks found one lonely statute during the proprietary period for the encouragement or protection of book-lovers. There was a library at Edenton of 76 volumes. Governor Gabriel Johnston had access to books, and so did James Iredell. The Rev. David Caldwell had a library, but this was destroyed by the British in $178 \mathrm{I}$. When Archibald Murphey was a student under Caldwell, though a few Greek and Latin classics were available, Murphey tells us that in general "the students had no books on history or miscellaneous literature." "There were, indeed," he continues, "very few [books] in the State, except in the libraries of lawyers who lived in the towns." He adds: "I spent nearly two years without finding any books to read, except some old works on theological subjects. ... Few of Dr. Caldwell's students had better opportunities of getting books than myself," and "with these slender opportunities of instruction it is not surprising that so few [North Carolinians] became eminent in the liberal professions"-an observation, it seems to me, of profound significance. As late as 1804 the library of the Dialectic Literary Society, one of the two foundation stones of this Library, was contained in a cupboard in a corner room in Old East, and consisted, wrote Dr. Hooper, of "a few half-worn volumes presented by compassionate individuals. The cupboards," he writes, "were not only small, but full of rat holes, and a large rat might have taken his seat upon Rollin's History, the corner stone of the Library, and exclaimed with Robinson Crusoe:

"I am monarch of all I survey, My title there's none to dispute."

Writing in the North Carolina Historical Review, in 1925, W. C. Jackson said flatly that "during the two hundred years of this first cultural era [in North Carolina] there was not in the state a library worth mentioning." Not until I 840 , according to the same magazine, did the commonwealth make any real appropriation for a library of any kind. In that year the legislature set aside \$1000-about half the price of an automobile today - for a library in the state capitol. In the first half of the nineteenth century the University seems to have spent on books a total of less than $\$ 4000$, or about $\$ 80$ a year. Even if the dramatic and the anecdotal in these accounts over-color historical accuracy, the story is not flattering; and when we discover that in 1860 that classic reporter on Southern life, Frederick Law Olmstead, in his Journey in the Back Country, saying that "the ratio of the number of the citizens who cannot read at all to the whole, appears, by the census 
returns, to be only three times larger at the South than at the North" but that "I believe it to be much greater at the South than these returns indicate," whether we take the census returns or accept Olmstead's opinion, the picture is sorry enough. But when we turn from this indifference to books and literacy to the record of progress under Vance, Aycock, Mclver and their successors -a record presently culminating in this enlarged library building-we are strongly tempted to accept the providential view of history; and I, for one, am ready to quote the musical English of William Bradford, first governor of Plymouth colony, when he wrote: "Thus oute of smalle beginnings greater things have been produced by $\mathrm{His}$ hand that made all things of nothing, and gives being to all things that are; and as one small candle may light a thousand, so the light here kindled hath shone to many, yea in some sort to our whole nation, let the glorious name of Jehova have all the praise."

The penalty of doing well-and, as the record indicates, North Carolina has done exceedingly well-the penalty of doing well is not only that one must continue to do well but that one must strive to do better. Wonderful as is the achievement represented by this Library and this building, in another point of view there are certain considerations that must sober our judgment. In the academic world the libraries which count are necessarily libraries large enough, varied enough, and rich enough to permit the continual research into the records of past time without which our cultural tradition would perish. This Library is such a one. The maintenance of research is the chief characteristic differentiating a university from a college; and though a college would be helpless without a library, if we are to measure rightly the place of North Carolina in the world of university libraries, we must study the situation, not in conjunction with the small and general collections of books which suffice for college purposes, but on a national scale and in the context of national university standards. Some twenty-two colleges and universities now extant as institutions of learning were founded in this country before the creation of the University of North Carolina. The libraries of nine of these twenty-two are today of sufficient variety and size to appear along with this one in those national lists by which the significance of a university library can be properly measured; and it is an uncomfortable fact that the collections in every one of these nine institutions outrank those in Chapel Hill. Perhaps it is not disconcerting to learn from the American Library Directory that Harvard, Yale, Columbia, and Princeton outnumber this collection, but it is at least interesting to learn that the North Carolina Library is still exceeded by the collections at the University of Pittsburgh, at Brown University, at Dartmouth College, and at Rutgers in New Jersey. In a listing made two or three years ago of fifty-three libraries of sufficient importance to count in scholarly research, North Carolina ranked thirty-fifth; that is to say, it was almost three-fourths of the way down from the top; and of the libraries which surpass it, twenty-four out of thirtyfour were founded after the creation of the University of North Carolina, some of them in the life time of those here present. In terms of number of books the University of North Carolina Library is on a par with public libraries in Rochester, New York; Toledo, Ohio; Springfield, Massachusetts ; and Kansas City, Missouri, and far outranks any public library in the South; but it is in turn outranked by public libraries in Baltimore, Boston, Chicago, Cleveland, Detroit, and Los Angeles, to go no further. Now the mere number of books in a library 
is no necessary index of its intellectual value, and 1 have already said that in the scholarly world, it is the range and variety of a collection that count-its usefulness, in other words, to the scholar. Nevertheless, these figures furnish a rough index of relative place. I would not appear in the character of a croaking raven at the feast, and it might be well to content ourselves with general congratulations. But if while rejoicing with you I likewise indicate what is still the relative rank of this Library, it is not to find fault, but that you may see the work of building up a great collection in Chapel Hill is not finished as of today.

I am the more encouraged to say this because in the days when Vance and Aycock were pulling North Carolina out of the mud, those leaders rightly decided that North Carolinians were sufficiently stouthearted not to be satisfied with soft soap and flattery. They told the State where it then stood, educationally and otherwise; and public opinion soon rallied to men who were unafraid to speak the truth. Now that North Carolina has long since been pulled out of the mud and become a commonwealth to which the nation looks with interest whenever it wants a report on Southern progress, I cannot believe that the good sense of its citizens has altered; I am sure you will agree it is more important to know where we stand in relation to what is still to do than it is to rest satisfied with what has been done; and I am certain the incentive to go forward in building a greater University Library will be strong and lasting, and not terminate today.

There is, however, another and perhaps more primary question-it is the question: what is a university library? What is its relation to research? Why should the people of this or any other state be expected to pay for and continue to increase a collection of books and manuscripts only a tiny fraction of their number will ever read?

I suppose there is nobody here who is of the opinion of the mythical state legislator who refused to vote any more money to buy books for the state university library until he had assurance the professors had read all the books already shelved in it. But it is nevertheless true that the connection between a university library and the cultural health of the state which supports it is not always understood, even by college professors. To many a hard-pressed man of science, struggling with inadequate laboratory equipment, the appropriation for books in the university budget seems a sort of minor luxury, an extravagance necessary to keep those peculiar fellows, the humanists and the historians, happy ; and I have even heard a distinguished economist in an eastern university argue that the cost of the library could be greatly reduced by removing useless books from its shelves and by refusing to purchase books not immediately relevant to classwork. The retort is obvious, of course, but not illuminating that precisely as a chemist wants apparatus and materials when he wants them, whether they were used yesterday or will be used tomorrow, whether they are used by anybody else, or whether they cost little or much; and precisely as the economist wants his statistical tables and his reports when he wants them, so the scholar also wants what he wants when he wants it. We must, in all the professions, take each other's demands as necessary and dependable. But such a retort, though emotionally satisfying, does not shed light nor, let me add, does any firstclass scientist or statistician generally underestimate the scholar's need for useless books. Useless books?-useless to whom? Useless for how long? Useless for what purpose? Let me briefly examine a single case involving useless books and literary research having an incalculable influence. 
It used to be the pleasant custom at Chapel Hill, and for all I know it still is, to present each graduate of this University at commencement with a copy of the King James Bible along with his diploma. I suppose the King James Bible is the most influential book ever printed in the English tongue. It has not only been read by more people than any other book in English, but it has also been printed and reprinted more times than any other work in the language. Its ideas profoundly influenced the creation and government of the colonies out of which sprang the United States, and it remains today the standard of religious truth, of ethics, and of literary style for millions of Americans. How did this book come into being?

There had been a succession of translations of the Bible into English, wholly or in part, before this so-called authorized version of the Scriptures. Among these the earliest influential one was Tyndale's version, parts of it printed under extraordinary difficulties on the continent of Europe and smuggled in to Great Britain during the first third of the sixteenth century. Objection was made to Tyndale's version on both theological and scholarly grounds; that is, it was argued that Tyndale's English did not accurately represent the original Hebrew or the original Greek. Throughout the rest of the century various persons, individually or in partnership, sought to remove these objections by creating translations of their own. - But none of these proved universally satisfactory. Finally, after King James I came to the throne, there was held a conference at Hampton Court in 1604 designed to alleviate the religious tensions of the kingdom. At that conference Dr. John Reynolds, the head of Corpus Christi College, one of the constituent bodies making up the University of Oxford, suggested that a new translation be made. The king, who considered himself a scholarly man, thought this would be a good idea, provided it be done "by the best learned [men] in both the Universities [that is, at Oxford and at Cambridge], after them to be reviewed by the Bishops, and the chiefe learned [men] of the Church." So, eventually, it was agreed; and six companies of scholars and ecclesiastics were appointed, some fifty-four men in all, we are told. Two of these companies were at the University of Oxford, two were at the University of Cambridge, and two were at Westminster-that is, near the seat of the government of the English church.

But why Oxford and Cambridge? Why did not the churchmen do it all? Well, there were libraries at both universities, and we know something about them. For example, there exists a catalog, dating from I605, of the great Bodleian Library at Oxford, and from it we learn that this library was rich in precisely the kind of books that practical men never buy and see no use for. The library had (and still has) a rich and variegated collection of volumes in Hebrew, in Aramaic, in Syriac, in Latin, in Greek; it had a great collection of translations of the Bible; it had Biblical commentaries; it had dictionaries in all the learned tongues; and it had a variety of other volumes of erudition of no immediate interest to the Jacobean business man, but of immense interest for the task in hand. These libraries, in short, were the basis of what somebody called the trilingual colleges at both universities, meaning groups of scholars learned in Hebrew, Greek, and Latin ; and these libraries and these scholars made possible the King James Bible, probably the greatest single cooperative piece of literary research ever carried on by a group of scholars in modern times.

Theirs was a labor of years. Parts of the Bible were assigned to each of the several companies, and parts of these portions were 
in turn assigned to individual translators in each group, who worked each one to perfect his portion, then submitted the result to the whole company with which he was associated, and so on. These scholars brought to bear upon the task all the linguistic and library resources at their command. When the whole text had been completed and approved by the several companies, it was gone over one more time by a select committee of twelve, and later prepared for publication by two others especially appointed for the task, and in I6I I the King James Bible saw the light of day.

Suppose, however, the date had been I9I I instead of $\mathrm{I} 6 \mathrm{II}$; and suppose that practical men had had their way, banishing from the library these dusty tomes, forbidding library authorities to purchase "useless" volumes of this sort, requiring an accounting from the library authorities in strictly practical terms of all the moneys spent for books. Scholars would have had no tools to work with, or would have left the English universities and gone elsewhere, and in such circumstances I do not see how the King James Bible could have appeared. Can anyone imagine the history of Great Britain or of the United States in the last four centuries without the King James Bible? Yet if my economist friend had been present at a library board meeting in Oxford in 1604 , it is probable he would have protested against acquiring dictionaries nobody ever used and volumes nobody ever' read. To this day scholars continue to seek out the Bodleian Library precisely because it contains the kind of materials practical men would never have bought, and precisely as scholars from all over the United States come to Chapel Hill for the purpose of consulting materials of no apparent immediate concern to our neon-light civilization.

Of course we cannot hope immediately for another King James Bible. However excellent the doctoral dissertations which have come out of this or any other graduate school, no one pretends that any one of them, or all of them taken together, is of the order of magnitude represented by that great book. Moreover, to many people nowadays, and even to some university people, the doctoral dissertation is either a nuisance or a mystery. It assays a rather low grade of literary ore. But let us be just even to these dull things. The great collections of books which made the King James Bible possible were in turn made possible only by the patient accumulation of scholarly work, each in its way as dull, I dare say, as apparently useless, and as uninteresting to anyone except the compiler as doctoral dissertations are said to be today. It is impossible to predict. You cannot confidently declare that such and such a type of learned book is utterly useless.

For example: every time you consult an English dictionary, an encyclopaedia, a gazetteer, or a book of general reference you are, like the translators of the Bible, drawing upon the accumulated labor of forgotten scholars, men who spent their lives in acquiring, ordering, comparing, interpreting, and preserving the records of mankind. Every time the scientist discovers a new compound or invents a new device or discovers a new species, he runs to his friend, the scholar, in order to name the child; and the scholar is then expected to find or create an appropriate word. Our common speech thus pays tribute to the necessity of libraries. Did you, before coming here, receive a message over the far-writer, arrange your accommodations over the far-speaker, enjoy yourself last evening at the far-seer, and travel here in a self-mover? Or did you accomplish all this by far-feeling in advance? I will translate: Did you receive a telegram, arrange for rooms by telephone, enjoy television and come by automobile, or did you do all this by telepathy? The scholar in the library directly or indirectly furnished the 
language with these familiar words, and a thousand like them-appendicitis, stadium, radiogram, Caesarean operation, Oedipus complex, maximum, minimum, incinerator, motorcycle, bicarbonate of soda, teletype, anaesthetic. In a technological culture language must be adequate to technological processes, and philology, far from being something remote and useless, is as much a tool as a Stilson wrench, or calculus, or an interferometer.

I suppose that just as we come to take the King James Bible for granted, so by and by our ears become so accustomed to the technological vocabulary of modern America that we fail to appreciate the vital relation of libraries to applied science. Let me therefore turn to another area, the political life of the South, to show, if I can, the relation of university libraries to public welfare.

Fifty-two years ago there was begun at this University a series of scholarly monographs now known as the James Sprunt Studies in History and Political Science, a series made possible by the far-sighted wisdom of one of the leading benefactors of this institution. The intent of this series was, in the words of its founder, to "elucidate the history of North Carolina," and this aim has been kept constantly in mind for over half a century, alk eit the scope of the enterprise has been oroadened to include all the South. Let ', look at the first work to appear as a Spı unt monograph, and then let us look at some later historical work published at this University.

According to Kemp P. Battle, who may be presumed to know what he was talking about, the secession convention of I 86 I was not only one of the two or three most in . portant gatherings ever held in North Carolina, but it was composed, he says, of "more of the leading men of the state than any other representative body ever held within its limits." Who were these men?
No one had ever tried to find out in any thorough way until John G. McCormick, in the first James Sprunt Historical Monograph, undertook the task. With infinite labor he compiled biographical sketches of the delegates to this convention. This library at the time barely existed, the collection of papers at Raleigh was inadequate, scholarly journals were lacking, and as a result it took the author something over four years to put together a piece of writing not much longer than an article in $T h e$ Saturday Evening Post or Fortune. The difficulties that arise when materials are not collected in one place are clearly set forth in Mr. McCormick's opening remarks, from which I quote:

In writing this paper we have been forced to rely largely upon personal correspondence with the relatives of delegates or other persons, conversant with the facts, and in several instances all the necessary data have been obtained from the delegate himself. On commencing this undertaking in September, 1896 , all the North Carolina histories, pamphlets of the University and the Literary Societies, biographies, and other available matter were consulted. However, they contained but a small proportion of the material necessary for our work and much of this was unsatisfactory, and, in many cases... inaccurate. Correspondence was immediately begun, and was continued without interruption until May, I 897, and intermittently from then until the day of publication, during which time more than two hundred letters have been written. ... Owing to the fact that some people either misunderstood the motive of the work or allowed the matter to be overlooked, much trouble and delay have been caused, and needed data have not been obtained. For the same reason it was necessary to write many times to obtain the facts desired in each case.

Mr. McCormick went to work as the scholar must always go to work-that is, he went to the persons and the documents which would give him the primary facts, but the sheer expenditure of human energy required to write over two hundred letters, 
besides undertaking an indefinite number of personal interviews and consulting records scattered all over the State, often uncataloged and unrecognizable, is wasteful, if heroic, and inefficient, if admirable. If the scientist is entitled to have his materials ordered in a single spot, so, it would seem, is the scholar. Why not accumulate documents in some central depot?

This, in fact, is what has been accomplished, or rather what is being accomplished at university libraries here and elsewhere. If Mr. McCormick were writing at Chapel Hill today, he could produce a far richer study with the expenditure of far less energy. The untiring efforts of Roulhac Hamilton and of others have accumulated materials Mr. McCormick never dreamed of. Ten years ago, according to the Sprunt monographs themselves, there were a million and a half cataloged documents having to do with fourteen Southern states, together with half a million uncataloged documents, in Chapel Hill alone, and today, of course, that number has increased, albeit Professor Hamilton in his article in the Journal of Southern History in 1944, had still some heartbreaking stories to tell of the loss of letters and records through carelessness, ignorance, and neglect.

But scholarship is more than the praise of famous men. Today we are engaged in a struggle against communism. The most persuasive argument urged by those who are skeptical of the good faith of American democracy is to point to the inferior status of Negro citizens in the United States. Europeans and Asiatics cannot understand the complexities of this problem, which cannot be solved in any doctrinaire fashion, nor by federal court decisions, nor by congressional laws alone, but only as its components are understood in their historical context by men of good will able to spread their understanding among our citizenry.

In the South certainly, and to only a lesser degree in the North, one of the stumbling blocks in the road to improving race relations is the memory of Reconstruction-that period when, in state legislatures and under the shadow of federal bayonets, self-seeking white politicians and ignorant Negro legislators combined to rule the prostrate states. From the treatment of this period in ordinary history books two inferences have been drawn of important consequence in public affairs. The first is that Northerners do not and cannot understand the Negro problem; and the second is that the Negro is by nature incapable of political responsibility. Among the Southern states most victimized during these years was South Carolina, and cartoons and photographs of South Carolina reconstruction legislatures still circulate as proof of the truth of these inferences.

In 1932 the University of North Carolina Press published a book by two excellent Southern historians, Francis Butler Simkins and Robert H. Woody. It is entitled South Carolina during Reconstruction and it runs to over six hundred readable pages. So far as I can learn from historical scholars, this book has never been superseded. It is the study to which one must go if he is to comprehend what went on in South Carolina during the Reconstruction Era. It is definitive, among other reasons, because the authors consulted documents and other primary materials in six or more leading libraries, read the contributions of scores of students, and benefited from the criticisms and suggestions of Southern colleagues and historians of the South. They do not in any way conceal or sidestep the evils of Reconstruction-the graft, the poverty, the humiliation, the suffering. But when they have studied everything that they can find in the records, when they have weighed all the elements and estimated the long-run results of Reconstruction in South Carolina, they cannot agree with the simple and 
melodramatic theory that the Carpetbaggers and the Scalawags and the Negroes were utterly wicked men. Evil men were among them, weak men were among them, vengeful men were among them, but there were also among them men of integrity and ability, who benefited both South Carolina and the region. In their last chapter the authors say this:

The positive contributions of Reconstruction to the permanent life of the state were considerable. In notable instances political institutions created then have survived the uprooting following 1876 . The principle of the equality of all men before the law was then grafted into the judicial practice of the state and it has not since been extirpated. The same is true of the right of all to attend state-supported schools and, potentially at least, to enjoy all political and civil liberties. Although the makers of the constitution of I 895 roundly attacked the constitution of I 868 , the document they produced is scarcely more than a revision of the handiwork of the Radicals. Such notable parts of the constitution of 1868 as the provisions for the organization of the courts, the codes of judicial procedure, the system of county government and school administration, the terms, and manner of election of public officials, and the system of taxation were repeated in the constitution of I895. Many of the innovations of Reconstruction in social and economic matters not directly affected by political changes have survived to this day. The winning by the Negroes of the liberty to manage their own church affairs is an achievement which still has a powerful influence upon the character of every community of the state. The system of land tenure and labor contracts devised during Reconstruction exists today with few modifications. ... During Reconstruction the commercial towns and villages came into being. At present they dot the map of the state... (pp. 56I562 )

Now sober conclusions of this sort are something more than antiquarian lore. They have present meaning in the world situation. Of course the findings of Messrs. Simkins and Woody, and of others like them, are not theatrical and do not acquire newspaper publicity. Moreover, it occasionally takes a long time for sober truth to overtake popular legend. Yet, precisely as few intelligent Americans nowadays accept as truth the doctrine of British villainy which formerly satisfied our notions of the American Revolution, so, as we slowly come to understand that the Reconstruction period was not mere bloodand-thunder, we learn that the image of the Negro fixed by demagogues is not the image the historian paints. In proportion, then, as the Reconstruction bugaboo disappears, we are less likely to be frightened to death by a ventriloquist, and in proportion as men cease to hate, in that proportion they are less likely to be governed by the passion of unreason. In proportion as you diminish the occasion of tension, you diminish distrust. It is not so long ago that the education of the Negro by Yankee schoolma'ams was held to be a special grievance of the South; today, Southern states are in some sense competing with each other to improve his educational opportunities. I do not for a moment suggest that perfection is just around the corner, and I am only too well aware of the truth in H. G. Wells's famous observation that the question before humanity is who is going to win the race between education and destruction. What I am trying to show, however, is that scholarship does count; it shapes or reshapes its images of our political past, it has its practical uses here and now. Unless we propose to believe like the Russians that scholarship must fit into a preconceived system of values, else we shall have none of it, in that other race, that between the demagogue and the statesman, we had better bet on the statesman. One of the principal characteristics of the demagogue is that by nature he distrusts the scholar; one of the principal attributes of the statesman is that he can learn something from history.

I have so far spoken as if historical schol- 
arship were the sole purpose of a university library. Of course this is not so. A proper university library is more than a collection of records and documents, rare editions and irreplaceable manuscripts. It is even more than a repository of information for the economist, the sociologist, the astronomer, the folklorist, and the metaphysician. It is more than a collection of reference books and a library school. Long ago Thomas Carlyle remarked that the best university is a collection of books. When he said this, Carlyle had in mind something other than a set of the Congressional Record and a complete run of the sixty-six volumes of Psychological Monographs: General and Applied.

For Carlyle a library was a collection of the noblest productions of human thought as these have been shaped by the saints, the sages, and the poets of mankind. For him a library is a place to which you can confidently turn for a copy of Faust or of Homer, of Plato or of Dr. Johnson, of Dante, Lucretius, the Bhagavidgita, Thomas Aquinas-whom you will among the great names of human thought and human art in words. If you had told Carlyle that by a library you understood the public library downtown where you expected to find the best-seller of the month; or the books to be rented at the drugstore; or murders available at twenty-five cents in a rack at the railway station, he would have blasted the ground beneath your feet. And properly so. A university library exists properly for the tough-minded of our race, not for the sentimental nor for readers who pick up a book and complain if it makes them think. It is not a place for love stories, light fiction, or books of transient appeal except as volumes in these categories serve a larger purpose.

Perhaps the most perplexing development in our reading habits, nationally speaking, is that they represent the failure of nineteenth-century hope. In Carlyle's time it was believed that the masses of mankind were hungry for the solid instruction and philosophic pleasure books of permanent merit can give, and to extend the habit of serious reading was the intent of a variety of laudable institutions. For example, innumerable Mechanics Libraries were created in Great Britain and the United States in order that industrious workmen might improve themselves. So, too, the public library developed as a mode of general intellectual culture rather than as the emotional candy store giving out ephemeral fiction its modern patrons seem to feel it must be. The church or Sunday school library came into being to satisfy the urge for self-improvement, and so did innumerable lyceums, athenaeums, and other varieties of association or private libraries. Finally, the middle class in the same era created the domestic library-those sets of great writers (Gibbon, Addison, Burke, Macaulay, and by and by Dickens, Thackeray, George Eliot, and the rest) which, by their dignity and silence, now reproach us as a breed of lesser men. Indeed, up to World War I an important writer in England and America expected as a matter of course to appear before he died in a collected edition on the shelves of such a library, as the New York edition of Henry James and the Author's edition of Mark Twain exist to testify.

Today this attitude toward the book has dwindled or disappeared. I think the last two authors in American literature to appear in anything like collected editions were, if my memory is right, Ellen Glasgow and Willa Cather. Even the international vogue of Sinclair Lewis did not create a collected edition; and we have so little faith in literary art in this country that Europeans coming here to stock American classics for their libraries discover to their amazement that we do not keep the writings of 
our notable authors in print. The high cost of publishing partially accounts for this change; so, too, does modern architecture, which has abandoned the library as a special room and when it has to face the problem of books, commonly puts up a couple of planks between twin beds in the master bedroom, for books, magazines, pipecleaners, and an alarm clock. The architect is not wholly to blame. If the public demanded shelf space for books, it would get shelf space, but the public is characteristically more interested in housing those three enemies of the book-the automobile, the television set, and the combination radio and phonograph.

Pressures of mass appeal, censorship (official or unofficial), quickie publishing, and confused thinking about the high cost of manufacture have profoundly altered the national attitude towards the book. Attempts to keep the prices of books within the range of average pocketbooks are as old as publishing, but in the twentieth century these efforts have taken two new turns, each a disaster to the book as a serious intellectual affair. Bookstores in this country have declined in number; and publishers have sought to create new outlets through mass production. The mass production of hardcover books is made possible through the various book clubs, each of which starts out with solemn promises to distribute only the best books carefully selected by a jury of experts, and each of which gradually slides down hill, despite public pronouncements to the contrary. The book club is by definition devoted to novelty; and although there are one or two clubs distributing the classics or serious out-of-print books, these do not greatly alter the picture. And the picture from the point of view of the book industry is that nowadays the life of a book is about three, four, or five months. The book is today the equivalent of the oldfashioned quarterly magazine, and has no longer life than an issue of such a periodical.

The second form of mass production is the twenty-five cent book, from which great things were expected. It was supposed to reach down into a public that could not afford to buy hard-cover books, develop their taste, and feed that public in to the higher intellectual ranges. The twenty-five cent book has undoubtedly discovered a new public, but it has not developed that public into a serious and thoughtful reading group. If in Great Britain the twenty-five cent book satisfied a hunger for serious readingfor example, in the Penguin series-despite the occasional appearance of Shakespeare or Webster's Dictionary on the wire stands in airports, railway stations, drugstores and supermarkets where these books are found, the twenty-five cent book has done little to keep serious reading alive. The sensational cover is an index of the diffculty. Driving from Boston to New Orleans last January, my wife and I interested ourselves to find any twenty-five cent book that was more than a murder story, a story of violence, a sensational exposé, or a "hot" love story. We could find virtually nothing. Obviously, reading taste conditioned to picking out its books by the amount of exposed bosom on the glossy covers is not likely to find Matthew Arnold exciting or to understand what existentialism is all about. I suspect there is some connection between the twenty-five cent book, with its implication that books should not long challenge your attention, and the fact that the much advertised "great books" series seems to be, not the great books, but excerpts and selections from them, cut down to a reading taste conditioned as I have suggested.

To say that the general publisher or the public library or the proponents of great books study clubs are not interested in serious reading would be a gross misstatement of fact. But it is nevertheless true that serious writing in this country faces 
extraordinary difficulties; that serious nonfictional writing is more and more becoming a property of the university presses; and that university libraries are increasingly regarded as the chief bastions of serious writing and thinking in the nation. In state after state in this supposedly literate republic, if college and university libraries were to disappear, American citizens would be without access in any orderly way to the principal intellectual achievements of mankind except as occasional public libraries shelve fragmentary portions of this record. The primary purpose of a university library is, fortunately, not to please a set of whimsical patrons demanding now this novel and now that; its primary aim is steadily to collect, enrich, and preserve records of intellectual achievement from every culture and from every time. The primary necessity of the public library, on the other hand, in most cases is, and has to be, satisfying the demands of its readers for simple entertainment and simple instruction. If, in the intervals of this service or because of a lucky accident in acquiring funds for this special purpose, it also builds up collections of permanent worth, as the better public libraries have done, both the community and the library are to be congratulated upon performance above and beyond the line of duty, at least as public library patrons understand the business of the public library today. To put the matter plainly: an institution which, in response to public demand, stocks eight copies of Gone With the Wind is not likely also to buy eight copies of Locke's Essay on the Human Understanding-is, indeed, not going to have any money with which to buy one copy. A university library, however, is conceivable without popular novels, though it likes to have them as documents in taste but a university library without a copy of the $E_{\text {ssay }}$ on the Human Understanding would not be a university library.
I said the university library is a bastion of serious thinking. I suggest we may now change this figure and refer to it as a central powerhouse of intellectual energy, with lines of force running from it to all parts of the state, the region, and the nation. If the librarian in the little local library cannot find the information she or her patron desires, she writes as a matter of course to the university library. If a high school teacher cannot get materials she needs, she does the same thing. A hard-pressed college teacher trying to do research work beyond the resources of the college library expects as a matter of right to borrow books through the inter-library loan system. For that matter, so does any other university library. Not only do these representative examples show how the state university library is central to the commonwealth, they illustrate also the freemasonry among scholars. So it is that the student, the teacher, the research worker expects to come to this or that university library for a longer or shorter time, to be welcomed there, and freely to use its materials. Extension courses, correspondence courses, adult education courses represent another dimension of this public relationship; and I might list also the service of the university library to business firms, alumni organizations, and study clubs. Indeed, until one has spent a day or two, so to speak, with the librarian in such an institution and watched the ceaseless traffic in printed matter to and from the library, one has no notion of the immense activity in such a powerhouse. I spoke earlier, and I think rightly, of the university library as the conservator of useless books; but if anyone has drawn from this a picture of the library as a heap of aged tomes slowly mouldering on the desk of an absent-minded librarian, the image of books under a spider-web will quickly disappear after a single visit to the living place. The paradox of the state university library is 
that it is like the god Janus, two-faced; it is simultaneously a collection of useless books in the half-humorous sense in which I have used that term; and also a collection of living print in such incessant demand that one of the principal items in any library budget is the cost of maintaining these public services.

This aspect of the university library has come into existence simultaneously with a vast shift in publishing methods and reading habits among our people. Fifty years ago, leading publishers regarded the production of books as a profession and were characteristically gentlemen of learning and culture; today, although some publishers retain this admirable tradition, publishing is no longer a profession but a branch of manufacturing, and the publisher sells books after the manner in which everything from soft drinks to automobiles is sold. It is significant that the book industry survives, not by reason of profits from the direct sale of books as intellectual productions, but from subsidiary rights that often have little to do with the philosophic or artistic merit of the work-movie rights, television rights, reprint rights, radio rights, translation rights, abridgment rights, and so on. Book advertising competes with the gaudy advertising of the theater. The industry is struggling to keep alive in the world of mass entertainment-the radio, television, baseball, Hollywood, and the more than thirty magazines having circulations ranging from one million to fifty-five million.

We may, if we like, rest content with this situation. In that event books and learning will remain the possession of a small, Samurai class of intellectuals, but the books that are generally read will become the modern equivalent of the bread-and-circus formula by which, in legend, the Roman emperors kept the populace docile and satisfied. Unfortunately, there are millions of
Americans, including many university alumni, who, though they may not know it, are, in fact, substantially of this point of view.

Or we may say that precisely as General Electric maintains its laboratories not for its own benefit only but for the general benefit of science; precisely as we think it right to protect the investigator in medicine or biology from crudely competitive processes and, by surrounding him with quiet and the proper tools, permit him to do his disinterested work for the common good; precisely as we think it right to maintain the famous Institute of Advanced Studies at Princeton or the Brookings Institution at Washington as homes for specialists to work in without fear of pressure; so we must maintain the university library as a center for disinterested thought. Indeed, as government pours its millions into science and the social sciences, neglecting the humanities in fact, we must, if we are not to throw our whole cultural life into the discard, pour more money rather than less into university libraries. For they are the laboratories and the refuge of the scholar, the humanist, the writer, and the philosopher. We cannot allow ourselves to become either a nation of robots, a nation happy in a push-button culture, or a nation drowsily content merely with faster automobiles, more dial telephones, synthetic substitutes of still greater chemical complexity, and faster-working sleeping-pills. If the university library is not the only institution in which thought for its own sake and books for their historic merit are still taken seriously, it is one of the most important institutions taking this function seriously. If, without vision, the people perish, without philosophy, a nation cannot survive. Where except in such a collection of masterpieces as is here housed and made available to all mankind, shall philosophy, that homeless spirit, go? 